\title{
Job stressors, emotional exhaustion, and need for recovery: A multi-source study on the benefits of psychological detachment
}

\author{
Sabine Sonnentag ${ }^{\mathrm{a}, *}$, Iris Kuttler ${ }^{\mathrm{a}}$, Charlotte Fritz ${ }^{\mathrm{b}}$ \\ a Department of Psychology, University of Konstanz, Box 42, D-78457 Konstanz, Germany \\ ${ }^{\mathrm{b}}$ Department of Psychology, Bowling Green State University, Bowling Green, OH 43403, USA
}

\section{A R T I C L E I N F O}

Keywords:

Job stressors

Psychological detachment

Emotional exhaustion

Need for recovery

\begin{abstract}
A B S T R A C T
This paper examines psychological detachment (i.e., mentally "switching off") from work during non-work time as a partial mediator between job stressors and low work-home boundaries on the one hand and strain reactions (emotional exhaustion, need for recovery) on the other hand. Survey data were collected from a sample of protestant pastors $(N=136)$ and their spouses $(N=97)$. Analyses showed that high workload, emotional dissonance, and low spatial work-home boundaries were related to poor psychological detachment from work during non-work time. Poor psychological detachment in turn predicted high levels of emotional exhaustion and need for recovery. Psychological detachment was a partial mediator between job stressors and strain reactions. This study avoids same-source bias and demonstrates the importance of psychological detachment in the stressor-strain relationship.
\end{abstract}

Job stress is a wide-spread phenomenon in today's jobs, particularly in human-service work (Zapf, 2002). Employees who face job stressors such as a high workload and emotional dissonance often suffer from emotional exhaustion and experience a high need for recovery (De Croon, Sluiter, \& Blonk, 2004; Zapf, Seifert, Schmutte, Mertini, \& Holz, 2001). Job stressors may increase emotional exhaustion and need for recovery because when confronted with these stressors, employees have to invest extra effort and have to regulate their emotions in order to meet the job demands (Zohar, Tzischinski, \& Epstein, 2003). While such dynamics unfold during the fulfillment of work tasks, job stressors may impact emotional exhaustion and need for recovery via a second pathway as well. This second pathway refers to the difficulty of psychologically detaching from work during non-work time, i.e., the inability to refrain from job-related thoughts when being away from the workplace (Sonnentag \& Bayer, 2005). We propose that job stressors make psychological detachment from work less likely which in turn will be related to emotional exhaustion and a high need for recovery.

Another factor relevant for psychological detachment from work during non-work refers to work-home boundaries (Ashforth, Kreiner, \& Fugate, 2000). Therefore, we will examine the relationships between spatial and technological boundaries, psychological detachment, and strain reactions (i.e., emotional exhaustion and need for recovery).

So far, research on psychological detachment has relied on self-report measures (e.g., Moreno-Jiménez, Rodrígez-Munro, Pastor, Sanz-Vergel, \& Garrosa, 2009; Sonnentag \& Fritz, 2007). However, if correlates of psychological detachment are assessed by self-reports as well, common method bias may obscure the underlying relationships. Therefore, we will try to overcome such weaknesses by adding a spouse-report measure of psychological detachment. We conduct our study with protestant pastors as one specific human-service profession (Cotton, Dollard, de Jonge, \& Whetham, 2003). Research has shown that the clergy face a high workload (Hill, Darling, \& Raimondi, 2003) and high emotional job demands (Ngo, Foley,

\footnotetext{
* Corresponding author. Fax: +49 7531885028.

E-mail address: sabine.sonnentag@uni-konstanz.de (S. Sonnentag).
} 
\& Loi, 2005). Clergy often report that professional demands intrude into their family lives (Hill et al., 2003; Lee, 1999). Related to these high levels of job-related stressors, high burnout rates are often observed within clergy (Beebe, 2007; Doolittle, 2007).

Our paper contributes to research on job stress, work-home boundaries, and job-stress recovery. First, we will examine if psychological detachment from work during non-work time partially mediates the relation between job stressors and strain reactions. Thereby, we aim at providing more insight into the processes by which job stressors translate into impaired wellbeing. Second, we add to research on work-home boundaries by examining if and how the lack of basic spatial and technological work-home boundaries hinder psychological detachment from work and by this mechanism might be related to strain reactions. Third, we overcome limitations of earlier research by avoiding same-source bias.

\section{Psychological detachment: Concept}

Etzion, Eden, and Lapidot (1998) introduced the term detachment into the respite literature and defined it as an "individual's sense of being away from the work situation" (p. 579). Psychological detachment from work refers to a state of mind during non-work time characterized by the absence of job-related activities and thoughts. It implies distancing oneself from the job not only in a physical, but also in a mental sense (Sonnentag \& Bayer, 2005).

\section{Job stressors as predictors of low psychological detachment}

Workload and emotional labor are two highly prevalent job stressors in clergy (Hill et al., 2003; Ngo et al., 2005). We propose that high workload will be negatively related to psychological detachment from work when at home. High workload refers to the experience of having too much to do in the time available (Spector \& Jex, 1998). Research has shown that high workload is associated with increased negative affect during work and that negative affect tends to spill over from the work to the home domain (Ilies et al., 2007), resulting in prolonged activation when being at home. This prolonged activation is then associated with thinking and ruminating about work-related issues (Brosschot, Gerin, \& Thayer, 2006) which makes psychological detachment from work difficult. In addition, when facing a high workload, employees may feel overwhelmed by the amount of work to be done and will continue to think about the tasks to be accomplished even when they are at home. Finally, as Sonnentag and Bayer (2005) have argued, high workload will be associated with an increased anticipation of the next working day, implying cognitions that are incompatible with psychological detachment from work. Empirical research has shown a negative relationship between workload and psychological detachment from work during non-work time (e.g., Sonnentag \& Fritz, 2007; Taris, Geurts, Schaufeli, Blonk, \& Lagerveld, 2008). Therefore, we propose the following hypothesis:

Hypothesis 1. High workload is negatively related to psychological detachment from work during non-work time.

We further assume that emotional dissonance - a typical stressor related to emotional labor (Zapf, 2002) - will be associated with poor psychological detachment from work. Emotional dissonance refers to a discrepancy between the requirement to express specific emotions at work and the genuinely felt emotions (Zapf, 2002). For example, emotional dissonance occurs when a pastor must show compassion with a person suffering from a severe illness, but does not experience any genuine warm and sympathetic feelings for this person.

Experiencing emotional dissonance may make it difficult to detach from work during non-work time. Particularly in a profession with strong norms to be compassionate and authentic (cf., Cotton et al., 2003), emotional dissonance will be associated with the subsequent feeling that one has not functioned optimally in a social encounter with a person seeking help or advice. The feeling of not having delivered a good, authentic "service" will make it more difficult to detach from work and may increase the likelihood to ruminate about the social encounter that one has not mastered optimally.

Hypothesis 2. Emotional dissonance at work is negatively related to psychological detachment from work during non-work time.

\section{Work-home boundaries as predictors of psychological detachment}

We propose that psychological detachment from work during non-work time is also contingent on the spatial and technological boundary arrangements between work and home. Scholars have argued that people create and maintain boundaries between their work and non-work roles (Ashforth et al., 2000). By erecting "mental fences" (Zerubavel, 1991, p. 2), individuals construct "slices of reality" (Ashforth et al., 2000, p. 474) associated with specific behaviors, thoughts and role requirements. Boundaries between work and home are not necessarily fully inflexible or impermeable. Rather, individuals differ in the degree to which they create and keep role boundaries - or in other words, integrate versus segment their different life domains (Rothbard, Philips, \& Dumas, 2005).

One obvious option of creating boundaries between work and home refers to spatial arrangements. Doing one's work only at a specific physical location outside of one's home (e.g., in company or church buildings separated from one's home) represents a situation of rather strong spatial boundaries. In contrast, temporarily working from a home office represents 
a situation with relatively weak spatial boundaries which makes it easier to cross boundaries multiple times during a day or evening. As a consequence, boundaries between work and non-work become weak.

In addition to such spatial arrangements, features related to the use of telecommunication devices impact work-home boundaries (Olson-Buchanan \& Boswell, 2006). It used to be quite uncommon (and often technically impossible) to use the same phone line or phone number at different locations. However, modern technology makes it possible to be reached via one number at any location, implying that one can receive work-related and non-work phone calls via one single phone line or number when being at home. As a consequence, when using such technological services, technological work-home boundaries are weak.

Hypothesis 3. Spatial and technological work-home boundaries are positively related to psychological detachment from work during non-work time.

\section{Psychological detachment from work and strain symptoms}

Our study focuses on emotional exhaustion and need for recovery as two strain indicators. Emotional exhaustion as a core dimension of burnout is a severe impairment of psychological well-being. Maslach, Schaufeli, and Leiter (2001) define emotional exhaustion as "feelings of being overextended and depleted of one's emotional and physical resources" (p. 399). Need for recovery refers to the desire to recuperate from work-induced fatigue, for example after returning home from work (Jansen, Kant, van Amelsvoort, Nijhuis, \& van den Brandt, 2003). Typically, need for recovery is described as a feeling of "wanting to be left in peace for a while" (Sluiter, Frings-Dresen, van der Beek, \& Meijman, 2001, p. 29).

During the past decades, studies have focused on predicting emotional exhaustion and need for recovery from workplace factors (De Croon et al., 2004; Demerouti, Bakker, \& Bulters, 2004). Recent research indicated also relationships between non-work experiences and these strain reactions (Sonnentag \& Fritz, 2007). Accordingly, we propose that psychologically detaching from work during non-work time provides a temporary break from job demands which allows recovery to occur (Meijman \& Mulder, 1998) which in turn should reduce the need for recovery and prevent emotional exhaustion. When an individual does not detach from his or her work during non-work time, work-related thoughts continue to drain resources which will increase the likelihood of emotional exhaustion. Moreover, lack of detachment implies that one returns back to work in a not fully recovered state the next morning. As a consequence, more effort has to be invested in order to meet job demands (Binnewies, Sonnentag, \& Mojza, 2009), which further depletes energy resources and contributes to an increase in need for recovery. First empirical studies support the assumption that psychological detachment from work during nonwork time is negatively related to strain reactions including emotional exhaustion and need for recovery (Fritz, Yankelevich, Zarubin, \& Barger, 2008; Sonnentag \& Fritz, 2007). Accordingly, we propose the following:

Hypothesis 4. Psychological detachment from work during non-work time is negatively related to emotional exhaustion.

Hypothesis 5. Psychological detachment from work during non-work time is negatively related to need for recovery.

\section{Psychological detachment as a partial mediator between job stressors, work-home boundaries, and strains}

We propose that psychological detachment acts as a partial mediator in the relationship between job stressors and strains as well as between spatial and technological work-home boundaries and strains. Countless studies have shown that job stressors are related to strains such as emotional exhaustion and need for recovery. For example, meta-analyses reported that a high workload is related to emotional exhaustion and other strain symptoms (Lee \& Ashforth, 1996; Podsakoff, LePine, \& LePine, 2007).

Moreover, there is consistent empirical evidence that emotional dissonance is associated with increased levels of emotional exhaustion (Bakker \& Heuven, 2006; Zapf et al., 2001). Research has shown that emotional dissonance increases strain symptoms (e.g., being tired) over the course of a working day (van Gelderen, Heuven, Van Veldhoven, Zeelenberg, \& Croon, 2007). Therefore, emotional dissonance should be related to increased levels of need for recovery.

Based on our above reasoning we suggest that the relationships between job stressors (workload, emotional dissonance) and strains (emotional exhaustion, need for recovery) are partially mediated by psychological detachment. Job stressors are assumed to be negatively associated with psychological detachment from work, and lack of psychological detachment in turn is assumed to be associated with high levels of emotional exhaustion and a high need for recovery. We suggest a partial mediation - as opposed to a full mediation - because low psychological detachment may not be the only mechanism that links job stressors and strains. For example, job stressors might increase emotional exhaustion and need for recovery by depleting affective and energetic resources immediately during the working day. Thus, we hypothesize the following:

Hypothesis 6. Psychological detachment from work during non-work time partially mediates the relationships between job stressors (workload, emotional dissonance) and strains (emotional exhaustion, need for recovery).

In addition, it can be assumed that low spatial and technological boundaries between work and non-work are related to emotional exhaustion and a high need for recovery. Specifically, we assume that low spatial and technical work-home 
boundaries may have a downside when it comes to emotional exhaustion and need for recovery. Based on data from two qualitative studies, Kreiner, Hollensbe, and Sheep (in press) described a broad set of strategies people use to manage work-home boundaries (for example, screening incoming phone calls at home and identifying work-related calls via caller ID). Such strategies might prove effective in achieving the desired level of segmentation versus integration, but enacting these strategies and constantly monitoring one's boundary level might be exhausting in itself and might increase one's need for recovery. Thus, boundaries will be negatively related to employee strain reactions. A survey study further showed that at workplaces where employees could mentally leave work behind when they go home, employee stress levels and work-home conflict were lower than at workplaces where such a segmentation was not possible (Kreiner, 2006). It is plausible to assume that at the former workplaces employees will be more likely to detach from work when being at home than at workplaces where it is expected that they continue to deal with work-related issues at home.

We propose that the relationship between work-home boundaries and strains is partially mediated by psychological detachment. As described above, work-home boundaries will be positively related to psychological detachment and psychological detachment will be negatively related to strain reactions. We suggest partial mediation - as opposed to full mediation - because psychological detachment may not be the only explaining mechanism. For example, low boundaries imply that family life can also intrude into the work domain which might increase emotional exhaustion and need for recovery as well.

Hypothesis 7. Psychological detachment from work during non-work time partially mediates the relationship between spatial and technical work-home boundaries and strains (emotional exhaustion, need for recovery).

\section{Method}

\subsection{Sample}

To recruit study participants we contacted all 359 pastors working in one large canton in Switzerland and sent them a survey package including a cover letter, a survey to be completed by themselves, a survey to be completed by their spouses, and a return envelope. A total of 142 self-report surveys and 102 spouse surveys were returned (40\% response rate for the self-report surveys). The final data set included usable data from 136 pastors (29.7\% women) and 97 spouses (78\% women). Pastors' mean age was 48.2 years $(S D=9.1)$; mean professional tenure was 17.8 years $(S D=10.3)$. Mean contract working time was $35.2 \mathrm{~h}$ per week $(S D=8.0)$. Mean actual working time per week was $50.3 \mathrm{~h}(S D=12.6)$. Most pastors $(84.2 \%)$ were married or cohabitating. Compared to all pastors employed in the canton, pastors in our sample did not differ with respect to gender $\left(\chi^{2}=2.174 ; d f=1 ; n s\right)$ and contract working hours (full time versus part time; $\chi^{2}=2.203 ; d f=1$; $n s$ ), suggesting that our sample was rather typical for all pastors working in this canton.

Spouses' mean age was 46.8 years $(S D=8.1)$; most of them $(71 \%)$ were employed, predominantly in educational and other service jobs. Pastors for whom spouse ratings of detachment were available did not differ significantly from pastors without spouse ratings with respect to age, professional tenure or weekly working hours. Not surprisingly, spouse ratings were more often available for pastors who were married or cohabiting than for those who lived alone $\left(\chi^{2}=3.624 ; d f=1 ; p<.001\right)$. Also, relatively more spouse ratings were available for male than for female pastors $\left(\chi^{2}=8.955 ; d f=1 ; p<.001\right)$.

\subsection{Measures}

Table 1 displays means, standard deviations, correlations, and Cronbach's alphas for all study variables.

\subsubsection{Job stressors}

We measured workload with five items from the ISTA scales (Semmer, Zapf, \& Dunckel, 1999). The ISTA scales are frequently used in German-speaking countries (Elfering, Semmer, Tschan, Kälin, \& Bucher, 2006) and comprise survey measures that correlate substantially with observer ratings of job stressors (Semmer et al., 1999). A sample item was "How often are you pressed for time at your work?". We assessed emotional dissonance with five items from the Frankfurt Emotion Work Scales (Zapf, Vogt, Seifert, Mertini, \& Isic, 1999). This emotional-dissonance scale has been extensively validated and is well embedded in a nomological net of emotion-related predictor and outcome variables (Zapf et al., 2001). A sample item was "How often does it occur in your job that one has to display positive emotions that do not correspond to what is felt in this situation?" For both types of job stressors we used a 5 -point Likert scale $(1=$ very seldom/never; $5=$ very often $)$.

\subsubsection{Spatial and technological boundaries}

We assessed spatial boundaries by asking if the participants had the office within their private home (coded as 0 ) or not (coded as 1 ). We assessed technological boundaries by asking if participants used the same phone number for work and private phone calls (coded as 0 ) or if they had separate phone lines (coded as 1 ).

\subsubsection{Psychological detachment}

We measured psychological detachment from work during off-job time using a self-report and a spouse-report measure. We used four well-validated detachment items developed by Sonnentag and Fritz (2007). Sample items were "During leisure 
Table 1

Means, standard deviations, zero-order correlations, and Cronbach's alphas for all study variables.

\begin{tabular}{|c|c|c|c|c|c|c|c|c|c|c|c|c|c|c|c|c|}
\hline & M & SD & 1 & 2 & 3 & 4 & 5 & 6 & 7 & 8 & 9 & 10 & 11 & 12 & 13 & \\
\hline 1 Gender & 1.70 & 0.46 & & & & & & & & & & & & & & \\
\hline 2 Living with a partner & 0.84 & 0.37 & .06 & & & & & & & & & & & & & \\
\hline 3 Number of children & 2.08 & 1.42 & .32 & .12 & & & & & & & & & & & & \\
\hline 4 Job tenure & 17.75 & 10.34 & .23 & -.09 & .29 & & & & & & & & & & & \\
\hline 5 Work hours & 50.28 & 12.58 & .31 & -.11 & .07 & .21 & & & & & & & & & & \\
\hline 6 Job control & 4.21 & 0.51 & .07 & .09 & .16 & .09 & -.01 & $(.72)$ & & & & & & & & \\
\hline 7 Workload & 3.15 & 0.76 & -.14 & .03 & -.21 & -.03 & .13 & -.24 & $(.83)$ & & & & & & & \\
\hline 8 Emotional dissonance & 2.67 & 0.62 & -.10 & -.12 & -.07 & -.06 & -.01 & -.28 & .28 & $(.83)$ & & & & & & \\
\hline 9 Spatial boundaries & 0.11 & 0.31 & -.13 & -.04 & .11 & -.15 & -.15 & .03 & .03 & -.01 & - & & & & & \\
\hline 10 Technological boundaries & 0.71 & 0.46 & -.00 & .07 & .12 & -.19 & -.19 & -.02 & .12 & -.00 & .12 & - & & & & \\
\hline 11 Emotional exhaustion & 1.39 & 0.51 & -.05 & .08 & -.19 & -.06 & .01 & -.34 & .47 & .32 & -.10 & .07 & $(.82)$ & & & \\
\hline 12 Need for recovery & 2.17 & 0.61 & -.16 & .02 & -.09 & .11 & -.02 & -.27 & .40 & .35 & -.18 & .03 & .59 & $(.82)$ & & \\
\hline $\begin{array}{l}13 \text { Psychological } \\
\text { detachment (self report) }\end{array}$ & 2.74 & 0.84 & .03 & -.08 & .02 & -.11 & -.17 & .21 & -.33 & -.29 & .19 & .13 & -.50 & -.53 & $(.87)$ & \\
\hline $\begin{array}{l}14 \text { Psychological } \\
\text { detachment (spouse- } \\
\text { report) }\end{array}$ & 2.61 & 0.94 & .07 & -.15 & .05 & -.10 & -.16 & .19 & -.30 & -.22 & .19 & .19 & -.43 & -.48 & .52 & $(.90)$ \\
\hline
\end{tabular}

Note. $N=136$ (except for spouse-report measure of psychological detachment). Correlations of $r \geqslant .17$ are significant with $p<.05$. Correlations of $r \geqslant .22$ are significant with $p<.01 . N=97$ for spouse-report measure of psychological detachment. Correlations of $r \geqslant .20$ are significant with $p<.05$. Correlations of $r \geqslant .25$ are significant with $p<.01$. Cronbach's alphas are in parentheses.

time, I get a break from the demands of work" (self report) and "During leisure time, s/he gets a break from the demands of work" (spouse-report). Respondents reported their answers on a 5-point Likert scale ( $1=$ I fully disagree; $5=$ I fully agree).

\subsubsection{Emotional exhaustion}

We measured emotional exhaustion with six items from the Oldenburg Burnout Inventory (OLBI; Demerouti, Bakker, Nachreiner, \& Schaufeli, 2001) - a measure that has been demonstrated to have good validity (Halbesleben \& Demerouti, 2005). A sample item was "At work, I feel emotionally drained". As suggested in the original version of the OLBI, we used a 4 -point Likert scale ( 1 = totally disagree; 4 = totally agree).

\subsubsection{Need for recovery}

Need for recovery was assessed with five items from Van Veldhoven and Broerson's (2003) scale. This measure showed good concurrent and predictive validity in earlier research (De Croon et al., 2004; van Veldhoven \& Broersen, 2003). A sample item was “Often, after a day's work I feel so tired that I cannot get involved in other activities". We used a 4-point Likert scale (1 = never; 4 = always).

\subsubsection{Control variables}

We assessed a range of control variables that might influence our predictor and outcome variables (gender, living with a partner, number of children, job tenure, working hours, job control). We used one-item measures for all control variables, except for job control. We assessed job control with four items from the ISTA scales (Semmer et al., 1999). A sample item was “To what extent can you influence how you accomplish your tasks?". Items were answered on a 5-point Likert scale ( 1 = very little; 5 = very much).

To examine if the self-report measures assessed by multi-items scales (workload, emotional dissonance, psychological detachment, emotional exhaustion, need for recovery, job control) can be differentiated at the construct level, we conducted confirmatory factor analyses. A six-factor model with all items loading on their respective factors showed a good model fit $\left(\chi^{2}=461.24, d f=362 ; p=.00031 ; \mathrm{CFI}=0.96\right.$; NNFI $=0.96$; RMSEA $\left.=0.049\right)$ and fit the data better than a one-factor model and all other models.

\section{Results}

We used two analytic strategies for testing our hypotheses: First, we used ordinary least square regression analysis for testing all hypotheses, conducting two sets of analyses: one with the self-report measure of psychological detachment and one with the spouse-report measure. Second, because self-report and spouse-report measures were not independent, we used a dyadic-data analysis approach for testing Hypothesis 1-3 (Kenny, Kashy, \& Cook, 2006) and modeled the two partners nested within the dyad, with the two detachment ratings as outcome variable in the same analysis, and control variables, rating source (self versus spouse), workload, emotional dissonance, spatial and technological work-home boundaries (all self ratings) as predictor variables. In all analyses, we controlled for gender, living with a partner, number of children, job tenure, actual work hours and job control. 
Hypotheses 1 and 2 stated that high levels of job stressors (workload, emotional dissonance) are negatively related to psychological detachment from work during non-job time. Hypothesis 3 proposed that spatial and technological work-home boundaries are positively related to psychological detachment. Ordinary least square regression analysis for the self-report measure of psychological detachment showed that our job stressors and boundary variables contributed significantly to the prediction of psychological detachment (left columns in Table 2). Workload and emotional dissonance were negatively related to psychological detachment while spatial boundaries were positively related to psychological detachment. Technological boundaries were not significantly associated with psychological detachment. Ordinary least square regression analysis for the spouse-report of psychological detachment (right columns in Table 2) showed that workload significantly predicted psychological detachment; also the signs of the other predictor variables showed into the expected direction, but did not reach the conventional significance level.

Dyadic data analysis using multi-level modeling largely supported the findings from ordinary least square regression analysis. In Model 1 including the control variables and the rating source as a dummy variable, actual work hours were negatively $(\gamma=-0.012 ; S E=0.005 ; t=2.40 ; p<.05)$, and job control was positively $(\gamma=0.368 ; S E=0.125 ; t=2.94 ; p<.01)$ related to psychological detachment. Rating source was not related to the detachment rating $(\gamma=0.153 ; S E=0.088 ; t=1.75$; $n s)$. The predictor variables entered in Model 2 improved model fit (difference in $-2 * \log (l h)=26.459 ; d f=4 ; p<.001$ ). Workload $(\gamma=-0.290 ; S E=0.084 ; t=3.45 ; p<.001)$ and emotional dissonance $(\gamma=-0.242 ; S E=0.092 ; t=2.63 ; p<.01)$ were negatively related to psychological detachment and spatial boundaries $(\gamma=0.498 ; S E=0.195 ; t=2.55 ; p<.05)$ were positively related. Technological boundaries showed no significant association with psychological detachment $(\gamma=-0.034$; $S E=0.135 ; t=0.26 ; n s)$. To test further if the associations between the core predictor variables and psychological detachment differed between self and spouse ratings, we computed interaction terms between the predictor variables and rating source and entered them into the multi-level models. Including these interaction terms into the models did not improve model fit, and none of the interaction terms was significant in itself, suggesting that the associations between workload, emotional dissonance, and spatial boundaries on the one hand and psychological detachment on the other hand did not differ for the two rating sources.

Hypothesis 4 predicted that psychological detachment from work during non-work time is negatively related to emotional exhaustion. Ordinary least square regression analysis showed that self-reported psychological detachment was a significant negative predictor of emotional exhaustion (Table 3, Model 2). A similar pattern of findings emerged for spouse-reports of psychological detachment (Table 4, Model 2). Hypothesis 5 stated that psychological detachment is negatively related to need for recovery. Analysis showed that the self-report measure (Table 5, Model 2) and the spouse-report measure (Table 6, Model 2) of psychological detachment were negatively related to need for recovery.

Hypotheses 6 and 7 proposed that low psychological detachment partially mediates the relationship between job stressors and work-home boundaries on the one hand and emotional exhaustion and need for recovery on the other hand. We tested these hypotheses with the Baron and Kenny (1986) approach. To show mediation, four conditions have to be met. First, the predictor variables have to be significantly related to the mediator. As the results displayed in Table 2 show, this condition was met for workload, emotional dissonance, and low spatial boundaries in the analysis with the self-report measure of detachment, and for workload in the analysis with the spouse-report measure. Second, the mediator has to be significantly related to the outcome variables. As Models 2 in Tables 3-6 show, this condition was met for emotional

Table 2

Results from hierarchical regression analysis predicting psychological detachment from job stressors and boundaries.

\begin{tabular}{|c|c|c|c|c|c|c|c|c|}
\hline & \multicolumn{4}{|c|}{ Self report } & \multicolumn{4}{|c|}{ Spouse-report } \\
\hline & \multicolumn{2}{|c|}{ Model 1} & \multicolumn{2}{|c|}{ Model 2} & \multicolumn{2}{|c|}{ Model 1} & \multicolumn{2}{|c|}{ Model 2} \\
\hline & $\beta$ & $t$ & $\beta$ & $t$ & $\beta$ & $t$ & $\beta$ & $t$ \\
\hline Gender & .109 & 1.175 & .069 & 1.410 & .111 & 0.997 & .073 & 0.671 \\
\hline Living with a partner & -.146 & -1.715 & -.124 & -1.536 & -.137 & -1.365 & -.120 & -1.262 \\
\hline Number of children & .023 & 0.247 & -.077 & -0.854 & .038 & 0.326 & -.062 & -0.546 \\
\hline Job tenure & -.137 & -1.521 & -.077 & -0.887 & -.140 & -1.244 & -.102 & -0.919 \\
\hline Work hours & -.186 & $-2.087^{*}$ & -.096 & -1.106 & -.166 & -1.594 & -.083 & -0.824 \\
\hline Job control & .225 & $2.669^{* *}$ & .116 & 1.410 & .172 & 1.669 & .111 & 1.117 \\
\hline Workload & & & -.264 & $-3.022^{* *}$ & & & -.287 & $-2.826^{* *}$ \\
\hline Emotional dissonance & & & -.199 & $-2.374^{*}$ & & & -.142 & -1.433 \\
\hline Spatial boundaries & & & .168 & $2.067^{*}$ & & & .162 & 1.609 \\
\hline Technological boundaries & & & .128 & 1.549 & & & .146 & 1.543 \\
\hline$R^{2}$ & & .111 & & .255 & & .105 & & .242 \\
\hline$F$ & & $2.689^{*}$ & & $4.274^{* * *}$ & & 1.769 & & $2.750^{* *}$ \\
\hline$\Delta R^{2}$ & & .111 & & .144 & & .105 & & .137 \\
\hline$F$ & & $2.689^{*}$ & & $6.039^{* * *}$ & & 1.769 & & $3.883^{* *}$ \\
\hline
\end{tabular}

Note. $N=136$ for self reported psychological detachment. $N=97$ for spouse-reported psychological detachment.

${ }^{*} p<.05$.

** $p<.01$.

$p<.001$. 
Table 3

Results from hierarchical regression analysis predicting emotional exhaustion from job stressors, boundaries, and psychological detachment (self report of psychological detachment)

\begin{tabular}{|c|c|c|c|c|c|c|c|c|}
\hline & \multicolumn{2}{|l|}{ Model 1} & \multicolumn{2}{|c|}{ Model 2} & \multicolumn{2}{|c|}{ Model 3} & \multicolumn{2}{|c|}{ Model 4} \\
\hline & $\beta$ & $t$ & $\beta$ & $t$ & $\beta$ & $t$ & $\beta$ & $t$ \\
\hline Gender & .004 & 0.040 & .054 & 0.672 & .059 & 0.705 & .084 & 1.085 \\
\hline Living with a partner & .137 & 1.644 & .069 & 0.930 & .107 & 1.397 & .062 & 0.861 \\
\hline Number of children & -.165 & -1.833 & -.154 & -1.941 & -.093 & -1.080 & -.121 & -1.517 \\
\hline Job tenure & .023 & 0.261 & -.040 & -0.516 & .006 & 0.073 & -.022 & -0.289 \\
\hline Work hours & .022 & 0.254 & -.154 & -0.818 & -.054 & 0.654 & -.089 & -1.161 \\
\hline Job control & -0.326 & $-3.951^{* * *}$ & -.222 & $-2.958^{* *}$ & -.198 & $-2.523^{*}$ & -.155 & $-2.120^{*}$ \\
\hline Workload & & & & & .364 & $4.384^{* * *}$ & .267 & $3.353^{* *}$ \\
\hline Emotional dissonance & & & & & .177 & $2.230^{*}$ & .104 & 1.388 \\
\hline Spatial boundaries & & & & & -.097 & -1.253 & -.035 & -0.484 \\
\hline Technological boundaries & & & & & .030 & 0.382 & .077 & 1.047 \\
\hline Psychological detachment & & & -.463 & $-6.092^{* * *}$ & & & -.366 & $-4.656^{* * *}$ \\
\hline$R^{2}$ & & .151 & & .191 & & .328 & & .428 \\
\hline$F$ & & $3.821^{* *}$ & & $9.493^{* * *}$ & & $6.106^{* * *}$ & & $8.440^{* * *}$ \\
\hline$\Delta R^{2}$ & & .151 & & .306 & & .274 & & .100 \\
\hline$F$ & & $3.821^{* *}$ & & $37.108^{* * *}$ & & $8.247^{* * *}$ & & $21.675^{* * *}$ \\
\hline
\end{tabular}

Note. $N=136$.

* $p<.05$.

** $p<.01$.

*** $p<.001$.

Table 4

Results from hierarchical regression analysis predicting emotional exhaustion from job stressors, boundaries, and psychological detachment (spouse-report of psychological detachment).

\begin{tabular}{|c|c|c|c|c|c|c|c|c|}
\hline & \multicolumn{2}{|c|}{ Model 1} & \multicolumn{2}{|c|}{ Model 2} & \multicolumn{2}{|c|}{ Model 3} & \multicolumn{2}{|c|}{ Model 4} \\
\hline & $\beta$ & $t$ & $\beta$ & $t$ & $\beta$ & $t$ & $\beta$ & $t$ \\
\hline Gender & .004 & 0.039 & .048 & 0.473 & .052 & 0.515 & .072 & 0.747 \\
\hline Living with a partner & .146 & 1.483 & .092 & 1.006 & .137 & 1.540 & .103 & 1.197 \\
\hline Number of children & -.200 & -1.768 & -.185 & -1.776 & -.123 & -1.162 & -.140 & -1.382 \\
\hline Job tenure & -.001 & -0.011 & -.056 & -0.548 & .044 & 0.420 & .015 & 0.148 \\
\hline Work hours & .046 & 0.453 & -.019 & -0.198 & -.020 & -0.211 & -.043 & -0.478 \\
\hline Job control & -.222 & $-2.196^{*}$ & -.155 & -1.634 & -.126 & -1.359 & -.095 & -1.057 \\
\hline Workload & & & & & .403 & $4.254^{* * *}$ & .322 & $3.390^{* *}$ \\
\hline Emotional dissonance & & & & & .199 & $2.155^{*}$ & .159 & 1.774 \\
\hline Spatial boundaries & & & & & -.100 & -1.063 & -.054 & -0.591 \\
\hline Technological boundaries & & & & & .061 & 0.650 & .102 & 1.123 \\
\hline Psychological detachment & & & -.392 & $-4.121^{* * *}$ & & & -.282 & $-2.930^{* *}$ \\
\hline$R^{2}$ & & .140 & & .287 & & .343 & & .404 \\
\hline$F$ & & $2.447^{*}$ & & $2.447^{*}$ & & $4.495^{* * *}$ & & $5.227^{* * *}$ \\
\hline$\Delta R^{2}$ & & .140 & & .138 & & .203 & & .060 \\
\hline$F$ & & $2.447^{*}$ & & $16.984^{* * *}$ & & $6.646^{* * *}$ & & $8.583^{* *}$ \\
\hline
\end{tabular}

Note. $N=97$.

${ }^{*} p<.05$.

*** $p<.01$

*** $p<.001$.

exhaustion and need for recovery as outcome variables and for both detachment measures. Third, the predictor variables have to be significantly related to the outcome measures and, fourth, this relationship should be reduced when the mediator is entered into the regression equation. To test the third condition, we regressed emotional exhaustion and need for recovery on job stressors and boundary variables. Table 3 (Model 3) displays the results for emotional exhaustion as outcome variable and the self-report measure of detachment. Workload and emotional dissonance were positively related to emotional exhaustion. A similar picture emerged in the analysis with the spouse-report measure of detachment (Table 4, Model 3), with workload and emotional dissonance being significant predictors emotional exhaustion.

To examine the fourth condition, we entered psychological detachment into the regression equations. The analysis for the self-report measure of psychological detachment (Table 3, Model 4) revealed that after entering psychological detachment into the model, the regression weight of workload decreased, but still remained significant. Emotional dissonance was no longer a significant predictor of emotional exhaustion. Sobel tests indicated significant indirect effects of workload $(z=2.532 ; p<.05)$ and emotional dissonance $(z=2.122 ; p<.05)$ on emotional exhaustion. For the spouse-report of detachment, after entering psychological detachment into the model (Table 4, Model 4), the regression weight of workload was 
Table 5

Results from hierarchical regression analysis predicting need for recovery from job stressors, boundaries, and psychological detachment (self-report of psychological-detachment measure).

\begin{tabular}{|c|c|c|c|c|c|c|c|c|}
\hline & \multicolumn{2}{|c|}{ Model 1} & \multicolumn{2}{|c|}{ Model 2} & \multicolumn{2}{|c|}{ Model 3} & \multicolumn{2}{|c|}{ Model 4} \\
\hline & $\beta$ & $t$ & $\beta$ & $t$ & $\beta$ & $t$ & $\beta$ & $t$ \\
\hline Gender & -.173 & -1.906 & -.118 & -1.492 & -.128 & -1.531 & -.100 & -1.308 \\
\hline Living with a partner & .073 & 0.868 & .004 & 0.060 & .048 & 0.618 & .000 & -0.002 \\
\hline Number of children & -.059 & -0.653 & -.051 & -0.649 & .023 & 0.265 & -.007 & -0.087 \\
\hline Job tenure & .187 & $2.108^{*}$ & .130 & 1.685 & .156 & 1.869 & .133 & 1.738 \\
\hline Work hours & -.003 & -0.032 & -.095 & -1.231 & -.092 & -1.108 & -.129 & -1.696 \\
\hline Job control & -.279 & $-3.346^{* *}$ & -.160 & $-2.156^{*}$ & -.155 & -1.968 & -.104 & -1.426 \\
\hline Workload & & & & & .302 & $3.599^{* * *}$ & .210 & $2.654^{* *}$ \\
\hline Emotional dissonance & & & & & .230 & $2.879^{* *}$ & .142 & 1.891 \\
\hline Spatial boundaries & & & & & -.188 & $-2.423^{*}$ & -.124 & -1.716 \\
\hline Technological boundaries & & & & & .012 & 0.150 & .063 & 0.858 \\
\hline Psychological detachment & & & -.498 & $-6.646^{* * *}$ & & & -.394 & $-5.063^{* * *}$ \\
\hline$R^{2}$ & & .130 & & .352 & & .258 & & .379 \\
\hline$F$ & & $3.239^{* *}$ & & $10.007^{* * *}$ & & $5.721^{* * *}$ & & 8.548 \\
\hline$\Delta R^{2}$ & & .130 & & .222 & & .182 & & .117 \\
\hline$F$ & & $3.239^{* *}$ & & $44.167^{* * *}$ & & $8.346^{* * *}$ & & $25.638^{* * *}$ \\
\hline
\end{tabular}

Note. $N=136$

${ }^{*} p<.05$.

*** $p<.01$.

*** $p<.001$.

Table 6

Results from hierarchical regression analysis predicting need for recovery from job stressors, boundaries, and psychological detachment (spouse-report of psychological detachment).

\begin{tabular}{|c|c|c|c|c|c|c|c|c|}
\hline & \multicolumn{2}{|c|}{ Model 1} & \multicolumn{2}{|c|}{ Model 2} & \multicolumn{2}{|c|}{ Model 3} & \multicolumn{2}{|c|}{ Model 4} \\
\hline & $\beta$ & $t$ & $\beta$ & $t$ & $\beta$ & $t$ & $\beta$ & $t$ \\
\hline Gender & -.122 & -1.105 & -.075 & -0.744 & -.086 & -0.819 & -.062 & -0.625 \\
\hline Living with a partner & .106 & 1.053 & .046 & 0.501 & .096 & 1.043 & .057 & 0.646 \\
\hline Number of children & -.039 & -0.336 & -.023 & -0.221 & .035 & 0.314 & .014 & 0.137 \\
\hline Job tenure & .187 & 1.668 & .126 & 1.225 & .214 & $1.981^{*}$ & .180 & 1.749 \\
\hline Work hours & -.010 & -0.096 & -.085 & -0.882 & -.078 & -0.799 & -.107 & -1.146 \\
\hline Job control & -.156 & -1.620 & -.169 & -1.778 & -.156 & -1.620 & -.120 & -1.300 \\
\hline Workload & & & & & .203 & $2.977^{* *}$ & .199 & $2.045^{*}$ \\
\hline Emotional dissonance & & & & & .273 & $2.842^{* * *}$ & .227 & $2.460^{*}$ \\
\hline Spatial boundaries & & & & & -.158 & -1.622 & -.106 & -1.123 \\
\hline Technological boundaries & & & & & .029 & 0.302 & .075 & 0.806 \\
\hline Psychological detachment & & & -.429 & $-4.480^{* * *}$ & & & -.323 & $-3.259^{* *}$ \\
\hline$R^{2}$ & & .110 & & .274 & & .207 & & .369 \\
\hline$F$ & & 1.862 & & $4.801^{* * *}$ & & $3.510^{* *}$ & & $4.514^{* * *}$ \\
\hline$\Delta R^{2}$ & & .110 & & .164 & & .179 & & .287 \\
\hline$F$ & & 1.862 & & $20.071^{* * *}$ & & $5.432^{* * *}$ & & $10.623^{* *}$ \\
\hline
\end{tabular}

Note. $N=97$.

* $p<.05$.

${ }^{* *} p<.01$.

*** $p<.001$

reduced in size, but remained significant. A Sobel test indicated a significant indirect effect of workload on emotional exhaustion $(z=2.342 ; p<.05)$. All other variables did not qualify for mediation analysis as they were not related to psychological detachment (Table 2). Taken together, self-reported psychological detachment was a partial mediator in the relationship between workload and emotional exhaustion as well as between emotional dissonance and emotional exhaustion; spouse-reported psychological detachment was a partial mediator in the relation between workload and emotional exhaustion.

Results for need for recovery as outcome variable are displayed in Tables 5 and 6 . In the analysis using the self-report measure of detachment, workload, emotional dissonance, and low spatial boundaries were significant predictors of need for recovery (Table 5, Model 3). After entering psychological detachment into the model, the regression weight of workload decreased in size, and emotional dissonance and spatial boundaries were no longer significant predictors of need for recovery (Table 5, Model 4). A Sobel test yielded significant $z$-scores for workload $(z=2.575 ; p<.01)$ and emotional dissonance $(z=2.150 ; p<.05)$, but not for spatial boundaries $(z=-1.917 ; p=.055)$. When using the spouse measure of detachment (Table 6, Model 3), workload and emotional dissonance were significant predictors of need for recovery. After entering 
psychological detachment into the model, the regression weight of workload was reduced in size (Table 6, Model 4). A Sobel test $(z=2.399 ; p<.05)$ indicated a significant indirect effect of workload on need for recovery. Again, emotional dissonance did not qualify for a test of mediation in this set of analyses because it was not significantly related to the spouse-report of psychological detachment. Taken together, analyses speak for a partial mediation of self-reported psychological detachment in the relationship between workload and emotional dissonance on the one hand and need for recovery on the other hand, and for a partial mediation of spouse-reported psychological detachment in the relationship between workload and need for recovery.

\section{Discussion}

Our study showed that high workload, emotional dissonance, and low spatial work-home boundaries were negatively related to psychological detachment from work during non-work time. Low psychological detachment in turn was related to emotional exhaustion and need for recovery. In addition, psychological detachment partially mediated the relationship between workload and emotional exhaustion as well as between workload and need for recovery. Moreover, psychological detachment was a partial mediator between emotional dissonance and the self-report measure of emotional exhaustion and need for recovery.

The study demonstrated that a stressful job situation is not only reflected in high levels of emotional exhaustion and need for recovery, but also in low levels of psychological detachment from work during non-work time, that is, a state of mind in which people stay mentally connected to their job. This "mental connection" to one's job seems to translate job stressors into poor well-being. Of course, staying connected to one's job during off-job time may not always be negative and our study participants might have benefited in some way from not detaching from work (Binnewies, Sonnentag, \& Mojza, in press; Fritz \& Sonnentag, 2005). Results, however, suggest that the negative aspects of not detaching outweigh the positive ones, at least when it comes to strain symptoms such as assessed in this study.

Importantly, the relationship between workload and low detachment as well as between low detachment and strains did not only emerge in the self-report data set, but also when taking spouse-reports of detachment into account. Dyadic data analysis showed that rating source did not affect the relationships between the predictor variables and detachment ratings, suggesting invariant relationships across rating sources. Also, the finding that psychological detachment partially mediates the relationship between workload and strains was consistent across the two detachment measures. This pattern of results demonstrates that associations between job stressors, low psychological detachment and strains cannot be explained exclusively by same-source bias but seems to reflect substantive relationships.

With respect to work-home boundaries, spatial boundaries predicted psychological detachment and low need for recovery in the self-report data set. All other predictions referring to work-home boundaries were not supported. There are several explanations for the relative low importance of boundaries identified in this study. First, it might be that the specific, rather objective boundaries we assessed are not the most relevant ones. Maybe, psychological construals of boundaries are more important than facts about location of the office and phone lines. Second, other aspects of the technological interface might be more relevant than using the same phone number for work and home life. For example, checking emails and using Blackberries at home might impact work-home boundaries more severely. Third, it might be that the pastors in our sample have developed rather good boundary management strategies that helped them cope with low spatial and temporal boundaries.

\subsection{Limitations}

We need to note potential limitations of our study. A first concern is that we used a cross-sectional data set. Therefore, a causal interpretation of our findings would be premature. However, at least with respect to the causal order between job stressors and strains, there is broad evidence that job stressors predict changes in strain symptoms over time (De Lange, Taris, Kompier, Houtman, \& Bongers, 2003), whereas evidence for reverse causation is rather limited. More longitudinal studies are now needed that shed more light on the causal chain between job stressors, poor detachment, and strain levels. Second, one might argue that it is difficult to assess another person's psychological detachment from work during non-work time, because psychological detachment is primarily an internal process. However, particularly lack of detachment can be also observed by one's partner, for example when one is making job-related phone calls, performing other job-related activities, discussing job-related topics with the partner or when not being "fully present" at home. The zero-order correlation of $r=.52$ between self and spouse ratings of detachment supports the view that there is substantial overlap between the two persons' perceptions of one partner's level of detachment. Third, our study included a rather specific sample. Although it is worthwhile in itself to address the mechanisms that link high stressor levels with high strain levels in clergy, it will be interesting to replicate our findings in other occupational groups. We assume that the relevance of psychological detachment also becomes evident in other occupational groups facing a high workload and high emotional demands.

\subsection{Implications for research and practice}

Our results have implications for future research and practice. Future studies might want to look at other outcome measures such as social interaction within the family or strain reactions in other family members. For example, lack of 
detachment from work in one family member can impact social interaction and communication processes within the family because this member is still engaged in work-related thoughts or activities and therefore will be less involved in things taking place at home.

We found that job stressors were negatively related to psychological detachment from work. Given that nowadays many jobs are characterized by high levels of stressors, it is important that future studies identify factors that alleviate the relationship between stressors and low detachment. With respect to practical implications we suggest that human-service professionals learn to detach from work, especially when facing job stressors. Several approaches might help to detach: first, employees might want to plan and enact non-work activities that require full attention (e.g., specific hobbies); second, when coming home from work, employees may first want to share information about the working day with their spouses and afterwards move on to other topics for the rest of the night; third, in case work-related requests intrude into private life, employees may want to develop "rituals" that help to detach.

Taken together, it seems that it is not only the exposure to stressors on the job but the associated experience of not being able to detach from work when being at home that is responsible for increased strain levels.

\section{References}

Ashforth, B. E., Kreiner, G. E., \& Fugate, M. (2000). All in a day's work: Boundaries and micro role transitions. Academy of Management Review, 25, 472-491. Bakker, A. B., \& Heuven, E. (2006). Emotional dissonance, burnout, and in-role performance among nurses and police officers. International Journal of Stress Management, 13, 423-440.

Baron, R. M., \& Kenny, D. A. (1986). The moderator-mediator variable distinction in social psychological research: Conceptual, strategic and statistical considerations. Journal of Personality and Social Psychology, 51, 1173-1182.

Beebe, R. S. (2007). Predicting burnout, conflict management style, and turnover among clergy. Journal of Career Assessment, $15,257-275$.

Binnewies, C., Sonnentag, S., \& Mojza, E. J. (2009). Daily performance at work: Feeling recovered in the morning as a predictor of day-level job performance. Journal of Organizational Behavior, 30, 67-93.

Binnewies, C., Sonnentag, S., \& Mojza, E. J. (in press). Feeling recovered and thinking about the good sides of one's work: A longitudinal study on the benefits of non-work experiences for job performance. Journal of Occupational Health Psychology.

Brosschot, J. F., Gerin, W., \& Thayer, J. F. (2006). The perseverative cognition hypothesis: A review of worry, prolonged stress-related activation, and health. Journal of Psychosomatic Research, 60, 113-124.

Cotton, S. J., Dollard, M. F., de Jonge, J., \& Whetham, P. (2003). Clergy in crisis. In M. F. Dollard, A. H. Winefield, \& H. R. Winefield (Eds.), Occupational stress in the service professions (pp. 311-357). London: Taylor \& Francis.

De Croon, E. M., Sluiter, J. K., \& Blonk, R. W. B. (2004). Stressful work, psychological job strain, and turnover: A 2-year prospective cohort study of truck drivers. Journal of Applied Psychology, 89, 442-454.

De Lange, A. H., Taris, T. W., Kompier, M. A. J., Houtman, I. L. D., \& Bongers, P. M. (2003). "The very best of the millenium": Longitudinal research and the demand-control-(support) model. Journal of Occupational Health Psychology, 8, 282-305.

Demerouti, E., Bakker, A. B., \& Bulters, A. J. (2004). The loss spiral of work pressure, work-home interference and exhaustion: Reciprocal relations in a threeway study. Journal of Vocational Behavior, 64, 131-149.

Demerouti, E., Bakker, A. B., Nachreiner, F., \& Schaufeli, W. B. (2001). Job demands-resources model of burnout. Journal of Applied Psychology, 86, 499-512.

Doolittle, B. R. (2007). Burnout and coping among parish-based clergy. Mental Health, Religion E Culture, 10, 31-38.

Elfering, A., Semmer, N. K., Tschan, F., Kälin, W., \& Bucher, A. (2006). First years in job: A three-wave analysis of work experiences. Journal of Vocational Behavior, 70, 97-115.

Etzion, D., Eden, D., \& Lapidot, Y. (1998). Relief from job stressors and burnout: Reserve service as a respite. Journal of Applied Psychology, 83, 577-585.

Fritz, C., \& Sonnentag, S. (2005). Recovery, health, and job performance. Effects of weekend experiences. Journal of Occupational Health Psychology, 10, 187-199.

Fritz, C., Yankelevich, M., Zarubin, A., \& Barger, P. (2008). Detachment from work during leisure time. Paper presented at the Conference of the Society of Industrial and Organizational Psychology, San Francisco, CA.

Halbesleben, J. R. B., \& Demerouti, E. (2005). The construct validity of an alternative measure of burnout: Investigating the English translation of the Oldenburg burnout inventory. Work E Stress, 19, 208-220.

Hill, E. W., Darling, C. A., \& Raimondi, N. M. (2003). Understanding boundary-related stress in clergy families. Marriage E' Family Review, $35,147$.

Ilies, R., Schwind, K. M., Wagner, D. T., Johnson, M. D., DeRue, D. S., \& Ilgen, D. R. (2007). When can employees have a family life? The effects of daily workload and affect on work-family conflict and social behavior at work. Journal of Applied Psychology, 92, 1368-1379.

Jansen, N. W. H., Kant, I., van Amelsvoort, L. G. P. M., Nijhuis, F. J. N., \& van den Brandt, P. A. (2003). Need for recovery from work: evaluating short-term effects of working hours, patterns and schedules. Ergonomics, 46, 664-680.

Kenny, D. A., Kashy, D. A., \& Cook, W. L. (2006). Dyadic data analysis. New York, NY: Guilford Press.

Kreiner, G. (2006). Consequences of work-home segmentation or integration: A person-environment fit perspective. Journal of Organizational Behavior, 27, 485-507.

Kreiner, G., Hollensbe, E., \& Sheep, M. L. (in press). Do I build a bridge or secure the border? Negotiating the work-home interface via boundary work tactics. Academy of Management Journal.

Lee, C. (1999). Specifying intrusive demands and their outcomes in congregational ministry: A report on the ministry demands inventory. Journal for the Scientific Study of Religion, 38, 477-489.

Lee, R. T., \& Ashforth, B. E. (1996). A meta-analytic examination of the correlates of the three dimensions of job burnout. Journal of Applied Psychology, 81, $123-133$.

Maslach, C., Schaufeli, W. B., \& Leiter, M. P. (2001). Job burnout. Annual Review of Psychology, 52, $397-422$.

Meijman, T. F., \& Mulder, G. (1998). Psychological aspects of workload. In P. J. D. Drenth \& H. Thierry (Eds.), Handbook of work and organizational psychology, Vol. 2: Work psychology (pp. 5-33). Hove, England: Psychology Press.

Moreno-Jiménez, B., Rodrígez-Munro, A., Pastor, J.-C., Sanz-Vergel, A. I., \& Garrosa, E. (2009). The moderating effect of psychological detachment and thoughts of revenge in workplace bullying. Personality and Individual Differences, 46, 359-364.

Ngo, H.-Y., Foley, S., \& Loi, R. (2005). Work role stressors and turnover intentions: A study of professional clergy in Hong Kong. International Journal of Human Resource Management, 16, 2133-2146.

Olson-Buchanan, J. B., \& Boswell, W. R. (2006). Blurring boundaries: Correlates of integration and segmentation between work and nonwork. Journal of Vocational Behavior, 68, 432-445.

Podsakoff, N. P., LePine, J. A., \& LePine, M. A. (2007). Differential challenge stressor-hindrance stressor relationships with job attitudes, turnover intention, turnover, and withdrawal behavior: A meta-analysis. Journal of Applied Psychology, 92, 438-454.

Rothbard, N. P., Philips, K. W., \& Dumas, T. L. (2005). Managing multiple roles: Work-family policies and individuals' desires for segmentation. Organization Science, 16, 243-258. 
Semmer, N., Zapf, D., \& Dunckel, H. (1999). Instrument zur Stressbezogenen Tätigkeitsanalyse (ISTA) [Instrument for stress-oriented task-analysis (ISTA)]. In H. Dunckel (Ed.), Handbuch psychologischer Arbeitsanalyseverfahren (pp. 179-204). Zürich: vdf Hochschulverlag an der ETH.

Sluiter, J. K., Frings-Dresen, M. H. W., van der Beek, A. J., \& Meijman, T. F. (2001). The relation between work-induced neuroendocrine reactivity and recovery, subjective need for recovery, and health status. Journal of Psychosomatic Research, 50, 29-37.

Sonnentag, S., \& Bayer, U.-V. (2005). Switching off mentally: Predictors and consequences of psychological detachment from work during off-job time. Journal of Occupational Health Psychology, 10, 393-414.

Sonnentag, S., \& Fritz, C. (2007). The recovery experience questionnaire: Development and validation of a measure assessing recuperation and unwinding from work. Journal of Occupational Health Psychology, 12, 204-221.

Spector, P. E., \& Jex, S. M. (1998). Development of four self-report measures of job stressors and strain: Interpersonal conflict at work scale, organizational constraints scale, quantitative workload inventory, and physical symptoms inventory. Journal of Occupational Health Psychology, 3, 356-367.

Taris, T. W., Geurts, S. A. E., Schaufeli, W. B., Blonk, R. W. B., \& Lagerveld, S. E. (2008). All day and all of the night: The relative contribution of two dimensions of workaholism to well-being in self-employed workers. Work \& Stress, 22, 153-165.

van Gelderen, B., Heuven, E., Van Veldhoven, M., Zeelenberg, M., \& Croon, M. (2007). Psychological strain and emotional labor among police-officers: A diary study. Journal of Vocational Behavior, 71, 446-459.

van Veldhoven, M., \& Broersen, S. (2003). Measurement quality and validity of the "need for recovery scale". Occupational and Environmental Medicine, 60 , i3-i9.

Zapf, D. (2002). Emotion work and psychological strain. A review of the literature and some conceptual considerations. Human Resource Management Review, $12,237-268$.

Zapf, D., Seifert, C., Schmutte, B., Mertini, H., \& Holz, M. (2001). Emotion work and job stressors and their effects on burnout. Psychology and Health, 16, 527-545.

Zapf, D., Vogt, C., Seifert, C., Mertini, H., \& Isic, A. (1999). Emotion work as a source of stress: The concept and the development of an instrument. European Journal of Work and Organizational Psychology, 8, 371-400.

Zerubavel, E. (1991). The fine line: Making distinctions in everyday life. New York: Free Press

Zohar, D., Tzischinski, O., \& Epstein, R. (2003). Effects of energy availability on immediate and delayed emotional reactions to work events. Journal of Applied Psychology, 88, 1082-1093. 